\title{
Ringed sideroblasts in HIV infection - A rare phenomenon
}

Submitted: 17-12-2013

Sir,

Hematologic abnormalities are common in patients with HIV infection. Bone marrow abnormalities are frequent at all stages of the disease. Dysplasia, hypoplasia, maturation arrest, plasmacytosis, increased marrow eosinophils, lymphoid aggregates, histiocytes, hemophagocytosis and presence of granulomas in the bone marrow have been well documented. ${ }^{1}$ Iron stores are often increased however the presence of ringed sideroblasts is a rare phenomenon. ${ }^{2}$

A 20-year-old female patient presented with history of fever and weight loss of one year duration. On examination, the patient appeared pale and emaciated. On abdominal examination, massive hepatosplenomegaly and shifting dullness were found. Preliminary investigations showed hemoglobin $6.4 \mathrm{~g} / \mathrm{dl}$, total leukocyte count $23,480 / \mu \mathrm{l}$ and platelet count of $4,02,000 / \mu$ l. Peripheral smear showed neutrophilic leukocytosis with mild shift to left along with normocytic normochromic and few microcytic hypochromic red cells. Liver function tests and renal function tests were normal. Chest radiograph was normal and sputum/gastric aspirate were negative for acid fast bacilli. HIV-ELISA test was positive.

In view of anemia with hepatosplenomegaly, bone marrow aspiration was performed. Marrow was cellular with normoblastic erythropoeisis and normal maturation in myeloid and megakaryocytic series. No dysplasia was seen. There was increase in number of reactive plasma cells (Figure 1). Occasional histiocytes with hemophagocytosis were found (Figure 1-inset), whereas no abnormal cell or parasite was identified.

Ziehl Neelsen's stain for acid fast bacilli and PAS stain for fungus were negative. Perl's staining demonstrated normal marrow iron stores with presence of many ringed sideroblasts (Figure 2 and Figure 2-inset).

Sideroblasts are abnormal nucleated erythroblasts with granules of iron accumulated in perinuclear mitochondria. Ringed sideroblasts are sideroblasts containing 5 or more iron granules encircling one third or more of the nucleus. ${ }^{3}$

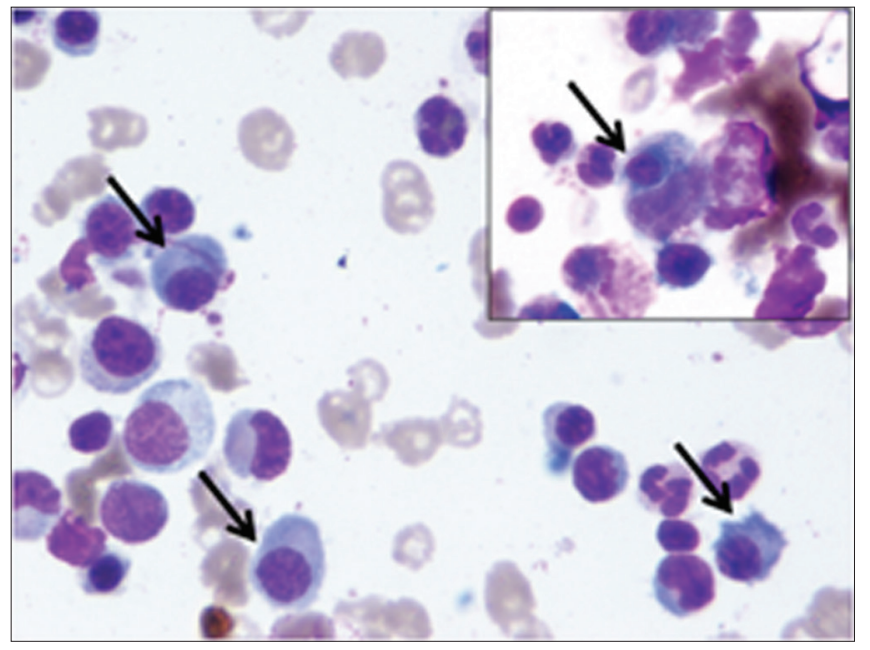

Figure 1: Cellular marrow with normoblastic erythropoeisis, normal maturation in myeloid and megakaryocytic series, with increased plasma cells (arrow) (Giemsa x 1000). Figure 1-inset: Cell showing hemophagocytosis (arrow) (Giemsa x 1000)

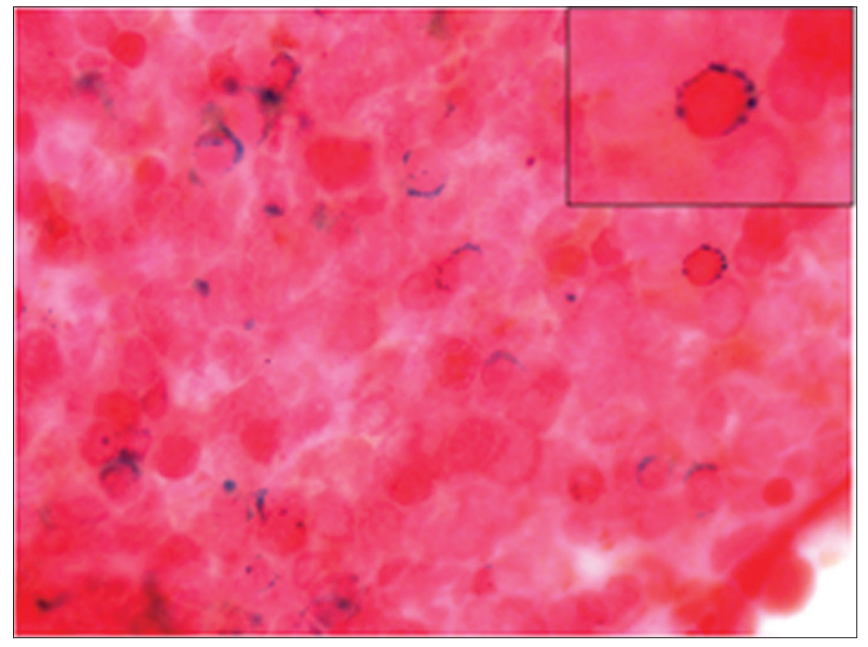

Figure 2: Ringed sideroblasts seen on Perl's Prussian Blue preparation (Prussian Blue x 1000)

Settings where Ringed Sideroblasts have been reported include Myelodysplastic syndromes, Myeloproliferative disorders, poisoning (lead, copper, or zinc) and drug toxicity (such as ethanol, isoniazid, chloramphenicol, cycloserine, linezolid and oral contraceptives). Ringed sideroblasts have also been reported with Pyridoxine or copper deficiency and 
diseases such as Rheumatoid arthritis or Multiple Myeloma. ${ }^{4}$ However, none of the above was found in our patient.

Marrow iron stores in HIV patients are usually adequate to increased, indicating a defect in iron utilization similar to that seen in other chronic disease states. ${ }^{5}$ However, sideroblasts with or without the presence of ringed forms have been very rarely described.

It is important for the clinicians and hematologists to be aware that ringed sideroblasts can be found in bone marrow with HIV infection per se. Differentiation from Myelodysplastic syndromes and Myeloproliferative diseases can be done by the absence of increased myeloblasts, Auer rods, micromegakaryocytes and abnormal immature cells in HIV infection alone.

\section{Neha Kawatra Madan', Sunita Sharma1, Manupriya Nain ${ }^{1}$}

${ }^{1}$ Department of Pathology, Lady Hardinge Medical College, New Delhi, India

\section{REFERENCES}

1. Patwardhan MS, Golwilkar AS, Abhyankar JR and Atre MC. Hematological profile of HIV positive patients. Indian J Pathol Microbiol 2002;45:147-150.

2. Tripathi AK, Misra R, Kalra P, Gupta N and Ahmad R. Bone marrow abnormalities in HIV disease. JAPI 2005;53:705-710.

3. Diagnosis and classification of myelodysplastic syndrome: International Working Group on Morphology of myelodysplastic syndrome (IWGM-MDS) consensus proposals for the definition and enumeration of myeloblasts and ring sideroblasts. Haematologica 2008;93:1712-1717.

4. Bottomley SS. Sideroblastic anemias. In: Lee GR, Foerster J, Lukens J, et al, eds. Wintrobe's Clinical Hematology. vol 1. $10^{\text {th }}$ ed. Baltimore, Md: Lippincott, Williams \& Wilkins; 1999: p. 10221046.

5. Treacy M, Lai L, Costello C and Clark A. Peripheral blood and bone marrow abnormalities in patients with HIV related disease. Br J Haematol 1987;65:289-294.

\section{Access this article online}

Website: http://nepjol.info/index.php/AJMS 